\title{
Thierry Paquot, Le paysage
}

Paris, la découverte, collection Repères, 2016, 125 p.

Jean-Pierre Husson

\section{QpenEdition \\ Journals}

Édition électronique

URL : http://journals.openedition.org/rge/6327

DOI : $10.4000 /$ rge.6327

ISSN : $2108-6478$

Éditeur

Association des géographes de l'Est

Référence électronique

Jean-Pierre Husson, «Thierry Paquot, Le paysage », Revue Géographique de l'Est [En ligne], vol.57 / 1-2 |

2017, mis en ligne le 15 novembre 2017, consulté le 25 septembre 2020. URL : http://

journals.openedition.org/rge/6327 ; DOI : https://doi.org/10.4000/rge.6327

Ce document a été généré automatiquement le 25 septembre 2020.

Tous droits réservés 


\section{Thierry Paquot, Le paysage}

Paris, la découverte, collection Repères, 2016, 125 p.

\section{Jean-Pierre Husson}

Dans un essai à la fois court et dense, le philosophe de l'urbain nous livre une réflexion originale sur cet objet à la fois poly sensoriel et bavard pour qui sait le prendre. Ce venant, il pose de nombreuses questions croisées sur la façon de prendre à bras le corps le paysage qui, au fil du temps est devenu un mot valise. Son travail érudit est nourri par des renvois à plus de trois cents titres insérés dans le texte et que l'on retrouve en bibliographie. Cette démarche fait du livre un outil à partager par tous ceux qui abordent ce sujet. Il use aussi d'une foule de références. $\mathrm{Vu}$ le sujet, l'auteur est obligé à tutoyer de nombreuses disciplines et, au premier chef les géographes (p. 23), par exemple Eric Dardel qui voyait dans le paysage un visage, un regard, une écoute, une attente,

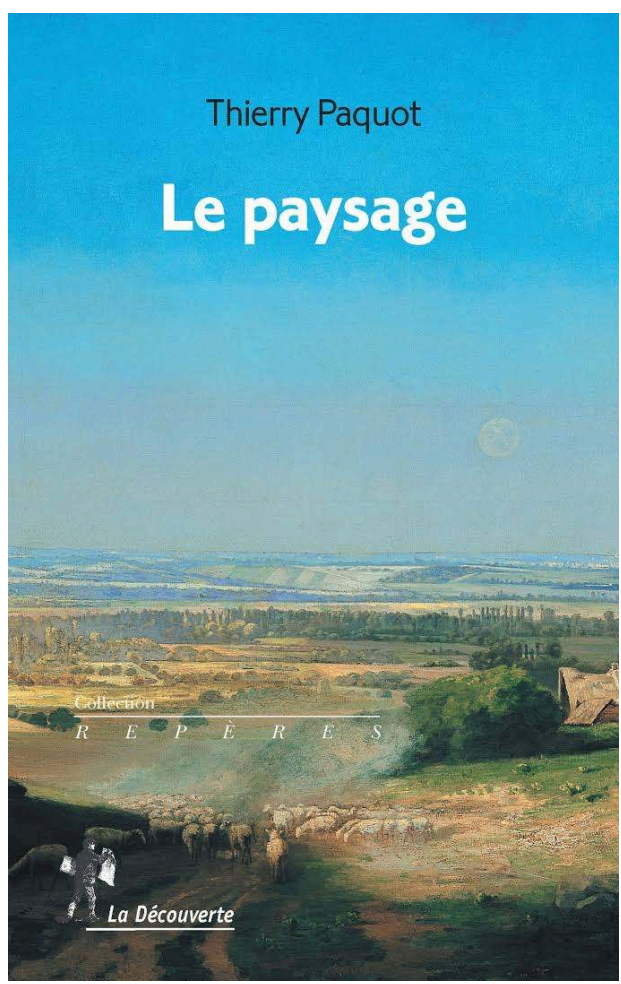
une souvenance.

2 Th. Paquot organise sa démonstration en cinq chapitres, débutant puisqu'il faut en passer par là, par un détour dictionnariste, autrement dit une analyse génésique du mot paysage, avec derrière lui des signes, des idées, des débats, des combats. Ce préalable établi, l'auteur peut s'engager dans un apport des disciplines au paysage émancipé de l'exclusif examen du regard pour évoluer vers des approches plurielles. Dans ce chapitre est évoquée la place privilégiée occupée par les géographes, avec les contributions essentielles de J.-Cl. Wieber et M. Ronai et encore les œuvres de Gaston 
Roupnel, Roger Dion, Jean-Robert Pitte. Th. Paquot se penche aussi sur les paysages industriels, religieux, sonores et politiques. Ensuite, il retourne vers sa discipline afin de mesurer la contribution des philosophes à la compréhension des paysages, nous éclairant sur le rôle tenu par quatre philosophes paysagistes : A. Roger qui diffusa l'idée d'artialisation, A. Berque (qui est également géographe) associé à l'idées de médiance paysagère, P. Sansot porté par la sensibilité des variations paysagères, enfin A. Cauquelin fort attachée au jardin, et encore les paysagistes B. Lassus, plasticien et coloriste et G.Clément, "faiseur de paysage», concepteur de l'idée de "jardin planétaire ». Le chapitre 3 intitulé Paysages et sentiment de nature (p. 45) invite à une progression chronologique partant des Antiques, passant par le Moyen Age réputé soumis à la cécité paysagère et la renaissance pour, in fine, s'interroger sur l'état d'âme du paysage. Comme dans le précédent chapitre, l'auteur mobilise des auteurs pour valider sa démonstration: le poète V. de Laprade, le géographe E. Reclus, le dixhuitièmiste D. Mormet, le philosophe F. Paulhan. En partant du genre pictural qui fait naître le paysage pour arriver à une patrimonialisation immatérielle (chapitre 4), l'alchimie des changements est longue, complexe. Ce cheminement toujours proche du récit nous invite à dire que tout paysage est un voyage dans le temps (p. 71) alliant la pratique du terrain et la poésie. Le dernier chapitre est plus personnel que les précédents car tous les cadrages du sujet ont été vus. L'auteur s'interroge sur les devenirs des paysages et le rôle de ceux qui les modèlent et les font évoluer. Les paysagistes travaillent et coordonnent toutes les échelles, croisant aménagement et environnement, rapprochant les expertises et suggestions des architectes et urbanistes. Depuis la parution récente de ce livre, il faut signaler que le titre de paysagisteconcepteur est désormais protégé par la loi du 8 août 2016. Ce métier concerne la maitrise d'ouvrage débutée par le projet, aboutie par l'aménagement, que l'on soit à l'échelle du jardin ou du territoire (p. 90). Les tâches assumées sont renouvelées par une législation foisonnante sur la durabilité (p. 95), et qu'il faut intégrer dans des approches systémiques des espaces à traiter. C'est par exemple le respect des trames vertes, bleues et noires si nécessaires à la bonne santé de la planète. En conclusion, le paysage est affaire de tous. Il dépend beaucoup des «paysangistes " (néologisme dû à Jacques Simon) pourtant trop souvent contraints par une agriculture très productive, mondialisée mais nécessaire pour nourrir les hommes. Il doit aux jardiniers et au final à nous tous qui voyons un paysage à notre porte (p. 104).

De façon optimiste, Th. Paquot termine son propos en rapprochant le coût et le goût du paysage à assembler dans un don de sensations (p. 107). Son objet d'étude partagé et trans-générationnel est une bonne lecture pour réfléchir ensemble à aménager et ménager des territoires où l'usufruit rappelle que nous sommes seulement de passage. 